\title{
Water Sorption of Polymethylmethacrylate and Polyamide Materials: A Comparative Study
}

\author{
Hamza Ulu ${ }^{1}$, Nuran Yanikoglu ${ }^{2}$, Nurdan Sagsoz ${ }^{3}$, Alper Ozdogan ${ }^{4}$
}

\begin{abstract}
Aim and objective: Structural disorders due to an allergic reaction and water absorption of denture base materials have created a negative effect on the patients. This study aimed to evaluate the water sorption values of different base denture base materials [polymethylmethacrylate (PMMA) and polyamide (PA)] which were kept at different immersion times.

Materials and methods: Eighty-eight specimens shaped as a disk with dimensions of ( $50 \mathrm{~mm}$ in length $\times 0.5 \mathrm{~mm}$ in thickness) were used in this study. PMMA and PA denture base materials were prepared according to the manufacturer's instructions. The control group was measured and recorded before immersing in solutions, the readings $\left(\mathrm{m}^{0}\right)$ of each specimen were measured using an electronic balance, and data were recorded. Then, the specimens were immersed for 1, 7, 30, and 45 days (d). The water sorption values of each specimen were measured before and after desiccation. Kolmogorov-Smirnov test and Mann-Whitney $U$ test were used for analyzing data.

Results: The PMMA specimens showed the highest sorption values in distilled water at 30 days $\left(0.30 \pm 0.03 \mathrm{mg} / \mathrm{mm}^{2}\right)$, while PA specimens showed the highest sorption values in the tea solution for 30 days $\left(0.51 \pm 0.06 \mathrm{mg} / \mathrm{mm}^{2}\right)$. PA and PMMA denture base materials showed statistically significant values $(p<0.05)$ after 30 days of immersion in water.

Conclusion: The sorption values of the PA materials were higher than those of the PMMA materials.

Keywords: Denture base material, PA, PMMA, Water sorption.

International Journal of Prosthodontics and Restorative Dentistry (2021): 10.5005/jp-journals-10019-1305
\end{abstract}

\section{INTRODUCTION}

Polymethylmethacrylate (PMMA) was introduced in 1936, as an alternative to vulcanized rubber and it has been used in constructing complete and partial removable denture bases. It is easily handled, with low thermal conductivity, esthetic properties, adequate strength, low solubility, lack of toxicity, and facility of fabrication and repair. It has low permeability to oral fluids and good color stability. ${ }^{1,2}$ Resin denture base materials are composed of monomers (methylmethacrylate) and polymers (PMMA). PMMA can be cured for hours in a water bath with controlled temperature degree or may expose to microwave energy for 4-5 minutes. $^{3}$

Despite superior physical properties, ease of fabrication, and repair; dentures fabricated from PMMA material have exhibited dimensional changes due to volumetric shrinkage resulting in space between the palate and the definitive cast as well as exerting heavy pressure on the lateral flange area. Such dentures have less than ideal support, retention, and stability. ${ }^{4}$

PMMA dominates the denture base resin materials market. If an alternative product is to succeed, it should not only have properties equal to those of PMMA, but it should also offer improved properties and advantages. ${ }^{5}$

Nylon and styrene are other materials used in dentures fabrication. Nylon was developed by Carruthers with the DuPont Chemical Co. In the 1950s, it was used as a denture base material. However, for this purpose, the material had many problems such as warpage, water sorption, discoloration, surface roughness, bacterial contamination, and difficulty in polishing. In 1971, Hargreaves ${ }^{6}$ used a different nylon polymer fabricated for dental use and specified guidelines for the optimum properties of the material. Since the scientific evidence about the properties of the thermoplastic resins
${ }^{1}$ Beşiroğlu Oral and Dental Health Center, Gebze, Kocaeli, Turkey

${ }^{2-4}$ Department of Prosthodontics, Faculty of Dentistry, Atatürk University, Erzurum, Turkey

Corresponding Author:AlperOzdogan, Department of Prosthodontics, Atatürk University, Erzurum, Turkey, Phone: +904422360942/1684, e-mail: alprozdgn@gmail.com

How to cite this article: Ulu H, Yanikoglu N, Sagsoz N, et al. Water Sorption of Polymethylmethacrylate and Polyamide Materials: A Comparative Study. Int J Prosthodont Restor Dent 2021;11(1):22-26.

Source of support: Nil

Conflict of interest: None

is insufficient due to the limited number of studies and the fact that these studies compare various clasp materials, so a current concern about these materials has developed. ${ }^{7,8}$

Several types of non-metal clasp dentures showing the advantages of superior esthetic properties and reduced potential allergic reaction in comparison to metals. Additionally, these denture types have the flexibility and highly elastic properties, which help to decrease the stress on the abutment teeth. ${ }^{2}$ Some other physicochemical and mechanical properties including Young's modulus and the flexural strength of denture base material also affected by water absorption., ${ }^{9,10}$ the International Standards Organization (ISO) specification No. 1567 stated $^{11}$ that water sorption should not exceed $32 \mathrm{pg} / \mathrm{mm}^{3}$ for heat- or chemical-cured materials.

This study is aimed to compare water sorption between PMMA and polyamide (PA) dental base materials. The research hypothesis is; PMMA specimens have higher water sorption values than PA specimens. 


\section{Materials and Methods}

PMMA (Meliodent; Bayer dental, Bayer UK limited, UK) and PA (Deflex; Nuxen S.R.L., Buenos Aires, Argentina) resin materials were used in this study. The specimens of $(50 \mathrm{~mm}$ in length $\times 0.5 \mathrm{~mm}$ in thickness) dimensions were prepared: PMMA specimens were prepared by heat-polymerized methods, while individual acrylic specimens were prepared by investing brass dies in a denture flask with the help of 3-mm thick spacer. PA materials were prepared by the injection-molded method. A total of (88) specimens were prepared and evaluated in this study; divided into 4 groups with (22) specimens for each.

The specimens were wet-polished with 100- to 1,200-grit waterproof abrasive paper to have three disk specimens with $50 \pm$ $1 \mathrm{~mm}$ dia, $0.5+0.1 \mathrm{~mm}$ thick for each group. The specimens were left in distilled water and tea solutions at a constant temperature of $37+1^{\circ} \mathrm{C}$ for $1,7,30$, and 45 days.

For the preparation of tea solution, five fabricated types of tea (Public tea; Çaykur, Rize, Turkey) were mixed with $500 \mathrm{~mL}$ of boiling water for 10 minutes. For the control group, a solution of distilled water was chosen. During the test period, all staining solutions were checked out and changed every week. Water sorption test was applied according to the directives of ISO specification No 1567:2005. ${ }^{12}$ Desiccation process is repeated till the weight of specimen decreases to $0.2 \mathrm{mg}$ or less as a constant weight. The mass $\left(\mathrm{m}^{0}\right)$ of each specimen was measured by using an electronic balance (Sartorius AG; Göttingen, Germany). Then, the specimens were immersed for 1, 7, 30, and 45 days in distilled water and tea solution. In the water absorption test; an increase in the weight of resin per unit surface area was chosen. This method is recommended by the American Dental Association. An increase in mass per unit volume is another method used in this study recommended by the ISO. ${ }^{13}$

The specimens were removed from the distilled water and then wiped with a cleaning tissue. Then, after 1 minute (designated as $\mathrm{mi})$, the mass of each specimen was measured again. Desiccation of the specimens was observed again for the round specimen container filled with tea, and then the mass of a constant weight $\left(\mathrm{m}^{2}\right)$ was measured. Water sorption values calculated by using the following formula:

$$
\begin{aligned}
\text { Wsp } & =\left(\mathrm{mrm}^{2}\right) / v \\
W s p & =\text { Water sorption }(\mathrm{mg} / \mathrm{mm})
\end{aligned}
$$

The diameter of the specimen was calculated by taking the mean of three different points. The mean thickness was obtained by measuring both; thickness of four equidistant points on the circumference and thickness at the center of the specimen (total of five points). The volume of each specimen $(V)$ was measured by calculating mean volumes of diameter and thickness. The testing procedure was repeated three times. ${ }^{14}$

Statistical analysis of data was conducted with the Kolmogorov-Smirnov homogeneity test and Mann-Whitney $U$ test using the IBM v.20 packaged software (SPSSv20.0; SPSS Inc., Chicago, IL, USA).

\section{Results}

In this study, water sorption values of PMMA and PA denture base materials were evaluated. Differences among solution storage values for each specimen measurement $(p<0.017)$ was also determined in this study. The values for the minimum, maximum, means, and standard deviation values of different denture base materials are shown in Table 1, test results are shown in Table 2.

PMMA specimens showed high sorption values for both; distilled water and tea solutions at a period of 30 days (distilled water, max: 0.30; tea, max: 0.21). Statistically significant differences at a period of 7 days $(p<0.017)$ were found, with no statistical differences at the period between 7 and 45 days ( $p>0.05$ ).

PA specimens showed values similar to PMMA. At 30 days, measurements showed the highest values (distilled water, max: 0.20 ; tea, max: 0.51 ) and the differences were statistically significant between 30 days and 7 days $(p<0.017)$.

Statistical analysis showed that PMMA specimens have higher sorption values in distilled water than PA specimens. However, PA specimens showed higher values in tea solution than PMMA specimens (Fig. 1). The differences between the PA and PMMA specimens were statistically significant at 30 days $(p<0.017)$, and differences were shown between 7 days and 45 days, but they were not statistically significant $(p>0.05)$. This investigation showed PA denture base materials absorbed much more solution than PMMA materials.

\section{Discussion}

With an increase in awareness of esthetic dentistry, the need for removable partial dentures (RPDs) that reveal little or none of the metal supporting structures or retentive elements arise. ${ }^{15}$

\begin{tabular}{|c|c|c|c|c|c|c|}
\hline Materials & Solutions & Time of storage (d) & $\operatorname{Minimum}\left(\mathrm{mg} / \mathrm{mm}^{2}\right)$ & $\operatorname{Maximum}\left(\mathrm{mg} / \mathrm{mm}^{2}\right)$ & Means & Std. deviations \\
\hline \multirow[t]{6}{*}{ PMMA } & Distilled water & 7 & 0.00 & 0.02 & 0.00 & 0.00 \\
\hline & & 30 & 0.10 & 0.30 & 0.13 & 0.03 \\
\hline & & 45 & 0.10 & 0.17 & 0.13 & 0.02 \\
\hline & Tea & 7 & 0.00 & 0.01 & 0.00 & 0.00 \\
\hline & & 30 & 0.08 & 0.21 & 0.09 & 0.02 \\
\hline & & 45 & 0.07 & 0.08 & 0.09 & 0.02 \\
\hline \multirow[t]{6}{*}{ PA } & Distilled water & 7 & 0.00 & 0.01 & 0.00 & 0.00 \\
\hline & & 30 & 0.02 & 0.20 & 0.09 & 0.02 \\
\hline & & 45 & 0.02 & 0.09 & 0.07 & 0.02 \\
\hline & Tea & 7 & 0.00 & 0.03 & 0.00 & 0.00 \\
\hline & & 30 & 0.04 & 0.51 & 0.08 & 0.06 \\
\hline & & 45 & 0.04 & 0.10 & 0.07 & 0.01 \\
\hline
\end{tabular}

Table 1: The minimum, maximum, means, and standard deviation values of the materials 
Table 2: The Wilcoxon test results of the groups

\begin{tabular}{|c|c|c|c|c|c|c|c|}
\hline & & \multicolumn{3}{|c|}{ PMMA } & \multicolumn{3}{|c|}{$P A$} \\
\hline & & 30-7 days & 45-7 days & 45-30 days & 30-7 days & 45-7 days & 45-30 days \\
\hline \multirow[t]{2}{*}{ Distilled water } & $Z$ & $-4.136^{\mathrm{a}}$ & $-4.110^{\mathrm{a}}$ & $-1.088^{b}$ & $-4.111^{a}$ & $-4.109^{a}$ & $-2.169^{\mathrm{a}}$ \\
\hline & Asymp. Sig. (two-tailed) & 0.000 & 0.000 & 0.276 & 0.000 & 0.000 & 0.030 \\
\hline \multirow[t]{2}{*}{ Tea } & $Z$ & & & & & & \\
\hline & Asymp. Sig. (two-tailed) & 0.000 & 0.000 & 0.075 & 0.000 & 0.000 & 0.331 \\
\hline
\end{tabular}

Different lower-case letters mean significantly different $(p<0.05)$

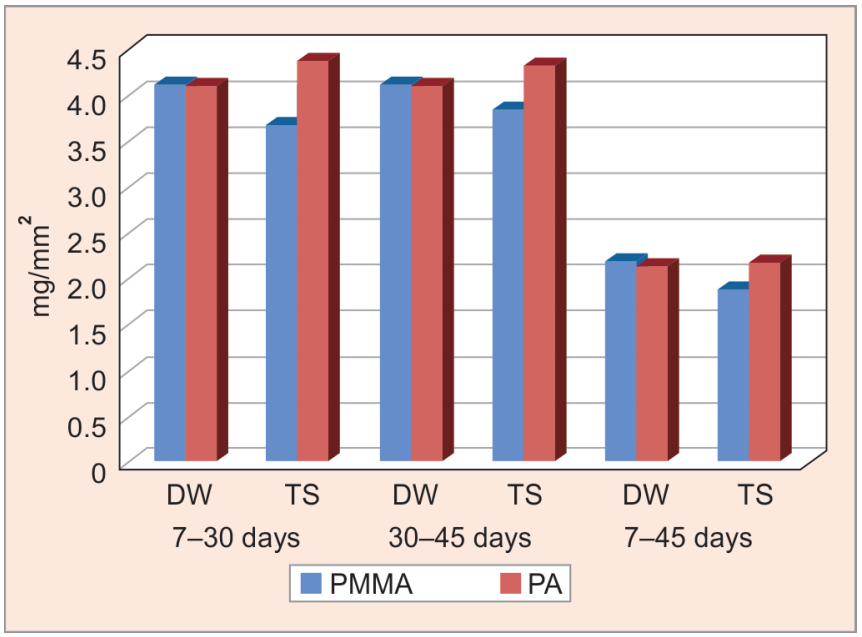

Fig. 1: Mean values according to time of storage ( $d=$ days)

Denture base polymers of different monomer compositions and polymerization systems showed different resistance degrees to water influence. ${ }^{16}$

In the uptake of water by resin materials, which is basically a diffusion-controlled process, water molecules diffuse through polymer during immersion in water or saliva while reaching the interface of the polymer matrix and then reinforce the fiber. The diffusion ability of water molecules within the polymer matrix is due to the presence of small size water molecules; the diameter of a water molecule is $<0.28 \mathrm{~nm} .{ }^{17}$ While water absorption into the polymer is a result of unbalanced intermolecular forces in the polymers. $^{18}$

This study showed that there is a time-dependent effect of the water sorption values for both PMMA and PA resins. Investigations revealed that variations seen in the deflection values for PMMA at 50 hours, as well as at 30,60, and 180 days of water storage were not statistically significant. ${ }^{10,14,19}$

An increase in the deflection values of the white and pink acetyl resins was determined when the water storage duration has increased from 50 hours to 30 days, and in the further stages, the same situation has happened. There was no significant increase in the deflection values between the 50 hours and 30 days' storage times, but a significant increase in deflection was stated between the time period of 50 hours and 60 days, as well as between 50 hours and 180 days. The increase in deflections of pink and white acetyl resins between 60 days and 180 days of water storage was significantly different from each other. ${ }^{19}$

In this study, significant differences were found between 7 days and 30 days and between 7 days and 45 days' measurements. However, no significant differences were found between 30 days and 45 days for each material.
It was propounded that water sorption of Promysan was significantly lower than Paladon 65 (PMMA). However, unlike water sorption; the water solubility of the hypoallergenic denture base materials such as Microbase, Polyan, Promysan, and Sinomer were not significantly lower than that of PMMA base material. Although all specimens were fulfilled the requirements of ISO 1567 water sorption and solubility. ${ }^{20}$

Takabayashi ${ }^{21}$ suggested that no significant difference was observed between the water sorption levels of LTF (PA) and AC (PMMA). LTF demonstrated the highest water sorption values. In this study, statistically significant differences were found between PMMA and PA materials in tea and distilled water solutions at 7 days and 30 days $(p<0.017)$. Upon evaluation, the results underlined that as the fiber contents increase in both groups, a decrease in water sorption was observed. However, the decrease in injection-molded specimens was clearer than the decrease in compression-molded specimens. $^{22}$

Cucci et al. ${ }^{23}$ suggested that Duraliner II autopolymerizing acrylic resin introduced a significantly lower water sorption value $(p<0.05)$ than Lucitone 550 (heat-polymerizing) acrylic resins. ${ }^{23}$ According to Dixon et al., ${ }^{22}$ water uptake and expansion could be affected by the remaining monomer. Since the liquid-to-powder ratio of the Duraliner II autopolymerizing resin showed higher value than the other materials, the low water sorption value of the Duraliner II autopolymerizing resin could be related to its higher residual monomer content which also may clarify the obtained results in the Duraliner II acrylic resin in an earlier report. It is stated that the water sorption and solubility of polymers are dependent on the homogeneity of the material, thus as material becomes more homogeneous, it absorbs less water as well as becomes less soluble. Nearly almost identical results were obtained from the different denture base materials for both tests of water sorption and solubility. Promysan (thermoplastic, enterephthalate-based) was the only material that significantly absorbed less water than the remaining materials. ${ }^{14}$ In this study, it was found that PA resins absorbed less distilled water than PMMA materials.

Yanikoglu et al. ${ }^{24}$ suggested that the weight of the acrylic specimens was higher on the first day. On a given day, sorption values were different from the other days because the water sorption of an acrylic specimen cannot exceed a specific value. Denture base polymers absorb water slowly over a period of time. This absorption is due to the polar properties of the molecules. The high equilibrium uptake of the water softens the denture base polymer because of the reason that the absorbed water acts as a plasticizer of the polymer. ${ }^{25}$

In this study, statistically significant differences were observed between the first and second measurements. This was according to the fact that acrylic resins absorb water slowly. Furthermore, no value differences were found during the third measurement. This explains acrylic has a specific sorption point. 
Nguyen et al. ${ }^{26}$ stated that the specimens were tested for water sorption and water solubility; there were statistically significant differences among the materials regarding water sorption, water solubility, and water saturation time. PA materials had statistically significantly lower water solubility than the PMMA. Zidan et al. ${ }^{27}$ reported that high-impact PMMA showed the lowest sorption and solubility in distilled water and artificial saliva. Yunus et al. ${ }^{3}$ observed PA denture base materials have a higher solution capability than other denture base materials. It was suggested in this study that PA-based resins absorbed much more solutions than PMMA-based resins.

Chuchulska et al. ${ }^{28}$ suggested that the thermocycling and the storage in a dry or in a wet environment of the samples result in a change of the diameter in almost every single type of material.

Elkholy ${ }^{29}$ has reported that water conditioning at $43^{\circ} \mathrm{C}$ is an important factor in decrease hardness meanwhile increases the flexibility of PA denture material. Hot and cold water conditioning had no significant effect on the dimensional stability of the PA denture base material. Cold water conditioning at $4^{\circ} \mathrm{C}$ could increase dimensional changes especially at the mid-palatal area of conventional heat cure PMMA due to shrinkage.

Song et al. ${ }^{30}$ stated that the water sorption of thermoplastic denture base resin was similar to that of PMMA heat-cured denture base resin.

PA tended to have inherently high water sorption values. As mention above, this phenomenon is explained by the water absorption occurring among the molecular chains due to the high hydrophobicity of the numerous amide bonds forming the main chains of the PA resin. It is also thought that the higher the amide group concentration, the greater the water sorption. ${ }^{21}$

Additional advantages of these denture materials are their flexibility and highly elastic nature, which decrease the stress on abutment teeth. After investigations into these types of materials were published, clinicians in Europe and the United States began using them for various clinical procedures, such as for orthodontic appliances and temporary dentures after implant placement instead of conventional dentures. ${ }^{31-34}$

To further improve the properties of (thermal properties, water sorption, solubility, impact strength, flexural strength) of PMMA, several chemical modifications and mechanical reinforcement techniques using various types of fibers, nanoparticles, and nanotubes have been reported recently. ${ }^{35}$

\section{Conclusion}

Within the limitations of this study design, the following statements were concluded:

PMMA has higher sorption values than PA in distilled water. PA has higher sorption values than PMMA in the tea solution than in distilled water.

PMMA and PA materials show significant water absorption properties. However, depending on the solutions in which they are kept, water absorption values may vary.

\section{ACKnOWLedgment}

Presented at 38th EPA Annual Conference of the European Prosthodontic Association (EPA) and 21st Scientific Congress of the Turkish Prosthodontic and Implantology Association (TPID) in İstanbul, Turkey, September 25-27, 2014.

\section{References}

1. Anusavice KJ, Shen C, Rawls HR. Philips' science of dental materials. 12th ed. St. Louis: Elsevier; 2013. pp. 108-110.

2. Chai XS, Hou QX, Schork FJ. Determination of residual monomer in polymer latex by full evaporation headspace gas chromatography. J Chromatogr A 2004;1040(2):163-167. DOI: 10.1016/j. chroma.2004.04.024.

3. Yunus N, Rashid AA, Azmi LL, et al. Some flexural properties of a nylon denture base polymer. J Oral Rehabil 2005;32(1):65-71. DOI: 10.1111/j.1365-2842.2004.01370.x.

4. Parvizi $A$, Lindquist $T$, Schneider $R$, et al. Comparison of the dimensional accuracy of injection-molded denture base materials to that of conventional pressure-pack acrylic resin. J Prosthodont 2004;13(2):83-89. DOI: 10.1111/j.1532-849X.2004.04014.x.

5. Wall DM. Clinical assessment of nylon as a denture base material. $\mathrm{Br}$ Dent J 1995;95:238-241.

6. Hargreaves AS. Nylon as a denture-base material. Dent Pract Dent Rec 1971;22(4):122-128.

7. Stafford GD, Handley RW. Transverse bend testing of denture base polymers. J Dent 1975;3(6):251-255. DOI: 10.1016/03005712(75)90030-5.

8. Takahashi H, Kawada E, Tamaki Y, et al. Basic properties of thermoplastic resins of denture base material referred to "non clasp denture". J Dent Mater 2009;28:161-167.

9. Barsby MJ, Braden M. A hydrophilic denture base resin. J Dent Res 1979;58(6):1581-1584. DOI: 10.1177/00220345790580060701.

10. Barsby MJ. A denture base resin with low water absorption. J Dent 1992;20(4):240-244. DOI: 10.1016/0300-5712(92)90094-s.

11. Sd-dbp International Organization for Standardization, second ed., International Standards Organization, Geneva, 1988.

12. Arikan A, Ozkan YK, Arda T, et al. Effect of 180 days of water storage on the transverse strength of acetal resin denture base material. J Prosthodont 2010;19(1):47-51. DOI: 10.1111/j.1532-849X.2009.00495.x.

13. Kalachandra S, Turner DT. Water sorption of polymethacrylate networks: bis-GMA/TEGDM copolymers. J Biomed Mater Res 1987;21(3):329-338. DOI: 10.1002/jbm.820210306.

14. Pfeiffer $P$, Rosenbauer EU. Residual methyl methacrylate monomer, water sorption, and water solubility of hypoallergenic denture base materials. J Prosthet Dent 2004;92(1):72-78. DOI: 10.1016/j. prosdent.2004.04.003.

15. Polat Sagsoz N, Yanıkoglu N, Ulu H, et al. Color changes of polyamid and polymetyhl methacrylate denture base materials. Open J Stomatol 2014;4(10):489-496. DOI: 10.4236/ojst.2014.410066.

16. Vallittu PK. Effect of 180 -week water storage on the flexural properties of E-glass and silica fiber acrylic resin composite. Int J Prosthodont 2000;13(4):334-339.

17. Ohno H, Endo K, Araki Y, et al. Destruction of metal resin adhesion due to water penetrating through the resin. J Mater Sci 1992;27(19):51495153. DOI: 10.1007/BF02403808.

18. O'Brien WJ, Ryge G. An outline of dental materials. Philadelphia: Saunders; 1978. pp. 221-222.

19. Polat TN, Karacaer O, Tezvergil A, et al. Water sorption, solubility and dimensional changes of denture base polymers reinforced with short glass fibers. J Biomater Appl 2003;17(4):321-335. DOI: $10.1177 / 0885328203017004006$.

20. Cucci AL, Vergani CE, Giampaolo ET, et al. Water sorption, solubility, and bond strength of two autopolymerizing acrylic resins and one heat-polymerizing acrylic resin. J Prosthet Dent 1998;80(4):434-438. DOI: 10.1016/s0022-3913(98)70008-3.

21. Takabayashi Y. Characteristics of denture thermoplastic resins for non-metal clasp dentures. Dent Mater J 2010;29(4):353-361. DOI: 10.4012/dmj.2009-114.

22. Dixon DL, Breeding LC, Ekstrand KG. Linear dimensional variability of three denture base resins after processing and in water storage. J Prosthet Dent 1992;68(1):196-200. DOI: 10.1016/00223913(92)90304-s. 
23. Cucci AL, Giampaolo ET, Leonardi P, et al. Unrestricted linear dimensional changes of two hard chairside reline resins and one heat-curing acrylic resin. J Prosthet Dent 1996;76(4):414-417. DOI: 10.1016/s0022-3913(96)90547-8.

24. Yanikoglu N, Duymus ZY, Yilmaz B. Effects of different solutions on the surface hardness of composite resin materials. Dent Mater J 2009;28(3):344-351. DOI: 10.4012/dmj.28.344.

25. Gilbert AS, Pethrik RA, Phillips RW. Acoustic relaxation and infrared spectroscopic measurements of plasticization of poly(methyl methacrylate) by water. J Appl Polymer Sci 1977;21(2):319-330. DOI: 10.1002/app.1977.070210202.

26. Nguyen LG, Kopperud HM, Øilo M. Water sorption and solubility of polyamide denture base materials. Acta Biomater Odontol Scand 2017;3(1):47-52. DOI: 10.1080/23337931.2017.1326009.

27. Zidan S, Silikas N, Haider J, et al. Long-term sorption and solubility of zirconia-impregnated pmma nanocomposite in water and artificial saliva. Materials 2020;13(17):3732. DOI: 10.3390/ ma13173732.

28. Chuchulska B, Yankov S, Todorov ,R. Injection shrinkage and water sorption of some thermoplastic dental materials. Pesquisa Brasıleıra Em Odontopedıatrıa E Clınıca Integrada 2019;19(1):e4474.
29. Elkholy S. Comparison of water conditioning effects on hardness and dimensional stability of methyl methacrylate and polyamide denture base materials. Int J Prosthodont Restorat Dentis 2018;8(4):114-119. DOI: 10.5005/jp-journals-10019-1218.

30. Song SY, Kim KS, LeeJY, et al. Physical properties and color stability of injection-molded thermoplastic denture base resins. J Adv Prosthodont 2019;11(1):32-40. DOI: 10.4047/jap.2019.11.1.32.

31. Meijer GJ, Wolgen PJ. Provisional flexible denture to assist in undisturbed healing of the reconstructed maxilla. J Prosthet Dent 2007;98(4):327-328. DOI: 10.1016/S0022-3913(07)60106-1.

32. Kaplan P. Flexible removable partial dentures: design and clasp concepts. Dent Today 2008;27(120):122-123.

33. Colán GP, Freitas FF, Ferreira PM, et al. Influence of different cantilever extensions and glass or polyaramide reinforcement fibers on fracture strength of implant-supported temporary. J Appl Oral Sci 2008;16(2):111-115. DOI: 10.1590/s1678-77572008000200006.

34. Fu CC, Hsu YT. A comparison of retention characteristics in prefabricated and custom-cast dental attachments. J Prosthodont 2009;18(5):388-392. DOI: 10.1111/j.1532-849X.2009.00459.x.

35. Zafar MS. Review prosthodontic applications of polymethyl methacrylate (PMMA): an update. Polymers 2020;12:1-35. 